\title{
Oral Phytorelief: Prevention of Upper Respiratory Tract Viral Conditions; Virucidal (Covid) and Germicidal Activity
}

\author{
Cesarone $\mathrm{MR}^{1}$, Hu S${ }^{1}$, Scipione $\mathrm{V}^{1}$, Scipione $\mathrm{C}^{1}$, Belcaro $\mathrm{G}^{1}$, Bombardelli E ${ }^{1}$, Cox $\mathrm{D}^{1}$, Cotellese $\mathrm{R}^{1}$, ${ }^{2}$ and Feragalli \\ $\mathbf{B}^{2}$ \\ ${ }^{1}$ Irvine $e^{3}$ labs and Oolex-Center \\ ${ }^{2}$ Dpt Sc Med Oral Biotec, Ch-Pe University \\ *Corresponding authors \\ Cesarone MR, Irvine3 labs and Oolex-Center, Dpt Sc Med Oral Biotec, Ch- \\ Pe University
}

Submitted: 17 March2021;Accepted:22 March 2021;Published: 01 Apr 2021

Citation: Hua CHENG (2021) Control Study of Short-Term Aftereffect in Diving Exposure Related Pulmonary Ventilation Function. Medical \&amp; Clinical Research 6(4): 489-497.

\begin{abstract}
This review presents results from recent supplement studies on PhytoRelief, an oral product including standardized natural extracts of pomegranate, curcuma and ginger. PhytoRelief $(P F)$ lozenges dissolve slowly in the mouth producing a protective mucosal gelffilm acting as a barrier against the most common upper respiratory tract (URT) viral infection.

GLOBAL EVALUATION: PR (as a pharma-standard supplement) appears to be effective - according to recent, controlled and prospective registry studies - as a virucidal (on Covid-19) and a germicidal (bactericidal) product - but more clinical studies in patients with different conditions are needed. Clinically, PR helps preventing a number of episodes of cold and flu and limits symptoms and the duration of the URT problem. This OTC product can be used without prescription - without risks of side effects - and it appears to be generally effective on most signs and symptoms of viral infections. PR has a good preventive value. No side effects or tolerability problem were observed in any patient. The important virucidal and germicidal activities to be better defined need larger and a more prolonged evaluation period in different contexts associated to viral infections. With predictive analytics and careful planning, it is possible to show the virucidal-bactericidal effects (and their clinical preventive efficacy) of PR in weeks. The planning of new studies - also evaluating the effects of PR on the immune system - is in progress.
\end{abstract}

Keywords: Pomagranate, Curcumin, Ginger, Upper Respiratory Infection, COVID-19, Flu, Cold, Oral Virucidals, Germicidals.

\section{Introduction}

The presence and replication of infective viruses in the upper respiratory tract (URT) may expose patients to several viral symptomatic or asymptomatic conditions including COVID-19. The URT is the main door to systemic infections and the mouth can be considered the main human incubator [1-4]. This review presents results from recent supplement studies on PhytoRelief, an oral product including standardized natural extracts of pomegranate, curcuma and ginger. PhytoRelief (PF) lozenges dissolve slowly in the mouth producing a protective mucosal film acting as a barrier against the most common upper respiratory tract (URT) viral infection.

STUDY 1: PHYTORELIEF in the prevention of URT, seasonal, winter viral infection (flu and cold: a 4 to 6-month registry study) (1). In this supplement, registry study (1) the aim was to evaluate the effects of the use of PR, a standardized, oral supplement.

Phyto-Relief includes anti-inflammatory, anti-oxidant and anti- edema natural compounds. Increased salivation produced by ginger (with production of saliva and lysozyme) is useful in the prevention and in the limitation of cold episodes and on the most common signs and symptoms associated to these episodes:

The action of the elements in PR is evident in minutes and it is shown by a significant increase in saliva output (with its content in antiviral-antibacterial elements, including lysozyme). The main targets of the first, pilot study were the evaluation of the occurrence of Cold/flu episodes and the reduction in signs/symptoms, the reduction of days of disease, the reduction in the use of other treatments and, finally, the evaluation and control of cold-related complications in a defined period of time. In a supplement study, two groups were formed: a standard management group and a standard management + Phyto relief group.

Three gummy lozenges (tablets)/day were used as the main prevention in the cold seasons (December to March). The tablets dissolve slowly in the mouth; they include pomegranate $(20 \mathrm{mg})$, 
curcuma Longa extract (50 mg) and ginger $5 \mathrm{mg}$. A daily dose of 3-4 tablets was used as the main prevention for 2 weeks. The third week of the registry was only observational.

Standard management to prevent 'seasonal', winter cold and flu (if there is any actual form or prevention) was considered avoiding obvious sources of contamination, washing hands after contacts, using $1 \mathrm{~g}$ /day of soluble Vitamin C (Cebion), a generally healthy lifestyle, regular exercise, also avoiding - if, when possible closed spaces with many individuals in winter.

The two resulting registry groups resulted comparable (Table 1). A total of 94 (44 females), otherwise healthy subjects used the $\mathrm{PH}+\mathrm{SM}$ and 98 (45 females) used only the SM. The number of clinical episodes (lasting more than 3 days), the total number of subjects with any episode, the episodes in the first and in the third week (without prevention) were all in favor of the preventive supplement $(\mathrm{p}<0.05)$. The average number of days and the lost working days were inferior with Phyto relief-CC. Also, the use of other OTC products and drugs, the number of complications after 4 days were significantly lower with PR $(\mathrm{p}<0.05)$.
Finally, the number of subjects with an extension of the diseased condition to more than 7 days with bronchial or tracheal complications was also significantly lower with $\operatorname{PR}(\mathrm{p}<0.05)$.

\section{No Safety or Tolerability Problem was Observed}

In this extended preliminary, registry study PR prevented a significant number 'minor 'episodes of cold and flu and helped (by shortening the duration events) the evolution of cold if used early, when initial symptoms could be identified.

More specific evaluations and larger prevention studies are in progress. The extension of the prevention to more than the two weeks of actual administration may indicate a more permanent effect of this supplement on improving local, mucosal, saliva (including lysozyme expression) and possibly, even in enhancing systemic immunity. In the two groups 35 out of 94 subjects in the PR group had received, at least one month previously, the flu vaccination and 38 out of 98 controls subjects had been vaccinated. Results indicated that the potential, preventive effects of PR seem to be independent from a previous anti-flu vaccination.

Table 1: observations in the two groups (PR prevention and standard management).

\begin{tabular}{|c|c|c|c|}
\hline TOTAL subjects & $\begin{array}{c}94 \text { (44 females) } \\
44.6 ; 3.3 \\
\text { PHYTORELIEF }\end{array}$ & $\begin{array}{c}98 \text { (45 females) } \\
45.3 ; 4 \\
\text { CONTROL }\end{array}$ & ns \\
\hline $\begin{array}{l}\text { 1. Episodes (>3 days) } \\
\text { of cold }\end{array}$ & $\begin{array}{c}13 / 94 \\
(13.26 \%)\end{array}$ & $\begin{array}{c}23 / 98 \\
(23.47 \%)\end{array}$ & $\mathrm{p}<0.05$ \\
\hline $\begin{array}{l}\text { 2. Total number of subjects } \\
\text { with any episode }\end{array}$ & $15 / 94$ & $26 / 98$ & $\mathrm{p}<0.05$ \\
\hline 3. Cold episodes (first week) & $9 / 94$ & $16 / 98$ & $\mathrm{p}<0.05$ \\
\hline $\begin{array}{l}\text { 4.Third week } \\
\text { cold episodes }\end{array}$ & $5 / 94$ & $13 / 98$ & $\mathrm{p}<0.05$ \\
\hline $\begin{array}{l}\text { 5. Other parameters } \\
\text { - Average days per episodes } \\
\text { - Lost working days }\end{array}$ & $\begin{array}{c}2.1 ; 1 \\
0.51 ; 0.4\end{array}$ & $\begin{array}{c}3.62 ; 1.1 \\
1.23 ; 0.44\end{array}$ & $\begin{array}{l}\mathrm{p}<0.05 \\
\mathrm{p}<0.05\end{array}$ \\
\hline $\begin{array}{l}\text { 6. Use of other OTC product } \\
\text { (nasal drops, aspirin, Vitamin C, } \\
\text { antihistamines, aerosols) }\end{array}$ & $16 / 94$ & $28 / 98$ & $28 / 98$ \\
\hline $\begin{array}{l}\text { 7. Number of complications } \\
\text { or extensions after } 4 \text { days }\end{array}$ & $3 / 94$ & $9 / 98$ & $\mathrm{p}<0.05$ \\
\hline $\begin{array}{l}\text { 8. Disease 'extension' (to }>7 \\
\text { days with tracheal or bronchial } \\
\text { complications) }\end{array}$ & $2 / 94$ & $5 / 98$ & $\mathrm{p}<0.05$ \\
\hline
\end{tabular}


THE SECOND STUDY: PHYTO-RELIEF in flu and cold: a 3 -month registry study in immunocompromised subjects (2). The second PR registry study included more difficult patients with compromised immune system and followed the pattern of the basic pattern of the first study.

The aim of this supplement, registry was to evaluate the preventive effects of the use of the standardized, oral supplement PR in blocking the development of cold (and its possible complications) in immunocompromised patients. A weakened immune systems is generally seen in subjects with AIDS, cancer (and in patients after chemotherapy), in transplant recipients (particularly those who are using immunosuppressive drugs); also subjects with inherited diseases that affects the immune system (e.g., congenital agammaglobulinemia, congenital IgA deficiency et cet.) are considered at higher risk of developing seasonal, viral diseases that may evolve into upper respiratory tract (URT) or pulmonary complications.

The risk of developing severe disease may differ depending on each person's degree of immune suppression. PR, as indicated, includes anti-inflammatory, anti-oxidant and anti-edema natural compounds. The increased salivation produced by ginger is useful in the prevention of viral, cold episodes and on signs and symptoms associated to the episodes by increasing the production of saliva and its content in lysozyme and other protective compounds. Subjects with limited salivation (dry mouth or xerostomia) are generally at higher risk of complications from viral infections.

The main targets of this second registry study were the evaluation of the occurrence of cold episodes and the reduction in signs and symptoms, the reduction of days of disease, the reduction in the use of other treatments (including drugs) and the evaluation and control of cold-related URT and pulmonary complications. The registry involved immunocompromised subjects (after surgery and chemotherapy and/or radiotherapy for solid, gastro-intestinal tumors).

As for the previous study, two groups were formed: a standard management group and standard management + Phytorelief-CC. Three gummy tablets (lozenges)/day were used as a prevention in the cold seasons (December to March). The lozenges dissolve slowly in the mouth (they include dantabija $20 \mathrm{mg}$, haridra 50 $\mathrm{mg}$, zingiber officinalis $5 \mathrm{mg}$ ). The 3-4 daily tablets were used as prevention for 2 weeks.

Standard management to prevent flu was considered by avoiding obvious sources of contamination, washing hands after any contacts, using a mouth/nose mask, using $1 \mathrm{~g} /$ day of soluble Vitamin C (Cebion), a generally healthy and active lifestyle including exercise and avoiding - if, when possible - closed spaces with many individuals in the winter registry period.

The two resulting registry groups were comparable (Table 2). The number of episodes (lasting more than 3 days), the total number of subjects with any episode, the episodes of cold seen within the first week (without prevention) were all in favor of the preventive supplement $(\mathrm{p}<0.05)$. The average number of days and the lost working days were also significantly lower $(p<0.05)$ with PR. The use of other OTC products (and drugs) and the number of clinical complications after 4 days were significantly lower $(\mathrm{p}<0.05)$ with PR.

Finally, the number of subjects with an extension of the diseased condition to more than 7 days (with bronchial or tracheal complications) was also significantly lower $(\mathrm{p}<0.05)$ with PR in comparison with SM. No safety problem or tolerability issues were observed during the registry. In conclusion, this pilot, registry study in immunocompromised subjects shows that $\mathrm{PR}$ is effective in preventing a significant number of cold/viral episodes and may help (by shortening them) the evolution of cold, if used early, when initial symptoms are identified.

More specific evaluations and larger prevention studies are in planning. The extension of the prevention to more than the two weeks of administration may indicate a more permanent effect of this supplement on improving local salivation, mucosal protection, lysozyme expression and possibly, even improving systemic immunity. All registry subjects had been vaccinated agaisnt flu at least one month before.

Table 2: observations in the two groups (Phytorelief prevention and standard management).

\begin{tabular}{|c|c|c|c|}
\hline & PR & SM & \\
\hline TOTAL subjects Age & $\begin{array}{c}12(5 \\
\text { females }) \\
46.7 ; 3\end{array}$ & $\begin{array}{c}14(7 \\
\text { females }) \\
47.4 ; 3.2\end{array}$ & ns \\
\hline $\begin{array}{l}\text { 1. Episodes ( }>3 \text { days) } \\
\text { of cold }\end{array}$ & $\begin{array}{l}3 / 12 \\
25 \%\end{array}$ & $\begin{array}{c}8 / 14 \\
57.1 \% \\
\end{array}$ & $\mathrm{p}<0.05$ \\
\hline $\begin{array}{l}\text { 2. Total number of subjects } \\
\text { with any episode }\end{array}$ & 3 & 8 & $\mathrm{p}<0.05$ \\
\hline $\begin{array}{l}\text { 3. Cold episodes in the first } \\
\text { week }\end{array}$ & 2 & 6 & $\mathrm{p}<0.05$ \\
\hline $\begin{array}{l}\text { 5. Other parameters } \\
\text { - Average days per episodes } \\
\text { - Lost working days }\end{array}$ & $\begin{array}{l}3.3 ; 2.1 \\
1.8 ; 0.5\end{array}$ & $\begin{array}{c}3.7 ; 1 \\
2.2 ; 0.5\end{array}$ & $\mathrm{p}<0.05$ \\
\hline $\begin{array}{l}\text { 6. Use of other OTC product } \\
\text { (nasal drops, aspirin, Vitamin } \\
\text { C, antihistamines, aerosols) }\end{array}$ & $\begin{array}{c}4 / 12 \\
33.3 \%\end{array}$ & $\begin{array}{c}10 / 14 \\
71.4 \%\end{array}$ & $\mathrm{p}<0.05$ \\
\hline $\begin{array}{l}\text { 7. Number of complications } \\
\text { or extensions after } 4 \text { days }\end{array}$ & 1 & 5 & $\mathrm{p}<0.05$ \\
\hline $\begin{array}{l}\text { 8. Disease 'extension' ( }>71 \\
\text { days with tracheal/bronchial } \\
\text { complications) }\end{array}$ & & 5 & $\mathrm{p}<0.05$ \\
\hline
\end{tabular}

\section{THE CODID 19 EPIDEMY}

The viral epidemy due to COVID has been a great challenge and could be now considered a model for controlling viral infection. COVID testing used in viral studies appear to be still not easy to manage in many conditions and difficult to evaluate in all subjects [6-10]. Virucidals can be used in specific situations to control the spread of viruses and particularly of the aggressive COVID-19 [11-18]. Salivary glands can be considered the main viral reservoir 
difficult to access for drugs/treatment and even for virucidals [1920]. A number of asymptomatic subjects may host the virus in the salivary glands, unpredictably releasing it in different moments. Germicidals may also affect and control the presence of bacteria in the mouth by direct contact. These aspects have been neglected in the past [21-23]. Several virucidals (and possibly bactericidal) products are available at low cost and appear to be safe and easy to use, without side effects [24-31]. In the occasion of the COVID epidemy we started to evaluate some virucindals and the possible virucidal effect of PR. The second part of the studies program involved the evaluation of the direct virucidal activity of PR on the saliva, specifically evaluating the presence of COVID-19 in the mouth $[3,4]$.

Study 3: COVID-19 Contagiousness in The Mouth: Virucidals Control the Presence of Covid in Saliva [3].

This pilot study evaluated the effects of some virucidals in vivo (using the RT-PCR swab test) to detect the presence of COVID in the mouth saliva. With this model, if an asymptomatic subject is positive (in the mouth saliva, the first incubating medium), virucidals can be used, i.e., for 3 days, and the positivity reevaluated to define the direct killing power of the virucidal. A progressive decrease in positivity in the swab samples was observed. Virucidals' produced disappearance of positivity in most subjects at 3 days. All virucidals used in this pilot registry resulted effective. However, the pharmaceutical form (lozenge) seems to be important to assure persisting traces of the virucidal in the mouth. The gummy PR lozenges possibly produce the longest topical action ( $>3$ hours) due to its slow release.

These preliminary observations indicate a significant effect of virucidals on the viral contamination of the mouth (the first incubator) with a relatively simple, cost-effective model.

COVID swabs detect the presence of COVID elements in saliva. The test is simple and fast but not completely reliable from a diagnostic point of view (one patient can be negative today and positive tomorrow). Testing identifies the SARS-CoV-2 virus and detects the presence of viruses (RT-PCR, isothermal nucleic acid amplification, antigen) or the presence of antibodies. The real-time reverse transcription polymerase chain reaction (rRT-PCR) test can be done on respiratory samples (including a nasopharyngeal swab or saliva/sputum samples) (1-3). Results are generally available within hours.

The presence of viruses in saliva a significant source of contagion can be evaluated; the oropharyngeal cavity is considered the real human incubator and the viruses multiply until they reach a critical mass to spread to target organs (trachea, bronchial tree and lungs). The salivary glands may also host the virus and operate as a secondary incubator; this may be linked to superspreading with prolonged release of viruses and sustained contagiousness. This registry evaluated the effects of some virucidals in vivo (using the RT-PCR test) to evaluate the presence of COVID in the saliva. With this model, if an asymptomatic subject is positive (in the mouth saliva, the first incubating medium), virucidals can be used, i.e., for a week, and the positivity re-evaluated to define the direct killing power of the virucidal.

PRESENCE OF THE COVID-19 VIRUS IN SALIVA AND
IN SALIVAL GLANDS. Viral elements in saliva is possibly associated to superspreading. In most of these subjects COVID-19 symptoms may be very mild (i.e., submandibular pain, swelling at the parotid and submandibular glands, sublingual glands, dry mouth, difficult swallowing). Salivary gland virosis may be very persisting for example with cytomegalovirus infection.

Asymptomatic 'patients' (found as positive), otherwise healthy, were evaluated. Their age was $<55$ and $>30$. No drugs had been used, a normal oral hygiene was regularly observed; their body temperature was normal. The test was made before $10 \mathrm{am}$, without washing mouth or teeth and without breakfast. The same tests were repeated at 3 days in similar conditions. No specific drugs were used during the observation period and no significant symptoms occurred or were reported. All subjects remained asymptomatic. Progression to symptoms and to need for management or hospitalization for COVID-19 (or any other condition) was considered an exclusion item. All subjects respected the anti-viral measures (mask, hygiene, distancing) and used Vitamin C and a normal diet.

Virucidals are generally available without prescriptions. Virucidal products - not for systemic use - were commonly available as Over the Counter (OTC) products. The selection was left to the single subjects.

1: PR: The gummy lozenge is slowly dissolved in the mouth; its effects may last 2-3 hours. The product includes pomegranate that considered both a weak virucidal and also an antiviral (if used for systemic administration) with anti-inflammatory activity: 3-64 tablets daily were used.

2.Benzydamine (also known as Tantum Green, branded in some countries as Difflam or Septabene), is available as the hydrochloride salt; it is a locally acting nonsteroidal anti-inflammatory drug (NSAID) with local anesthetic and analgesic properties for pain relief and anti-inflammatory management of mild conditions of the mouth/upper throat.

3.Baicalin (85\%) was obtained by XIXSI, Shanghai, China). This natural product (alone or in combinations) has been diffusely used in Wuhan during the epidemic (however data are not accessible). This is a flavone glycoside (the glucuronide of baicalein). This product is an Inhibitor of 5- and platelet 12-lipoxygenases (IC50 values are 9.5 and $0.12 \mu \mathrm{M}$ respectively). Also inhibits Rafmediated MEK-1 phosphorylation in glioma cells and induces G1 and $G 2$ cell cycle arrest by decreasing cdk1, cdk2, cyclin D2 and cyclin A expression. Inhibits production of inflammatory cytokines by inhibiting $N F-\kappa B$ activation. Also inhibits erastin-induced ferroptosis.

4 SUUSUIHKE mouth spray (Finland) includes the powerful antioxidant Pycnogenol in jelly solution).

5. A new compound used for dry mouth (Certmedica, Germany) shows persisting effects in the mouth (up to 3 hours). It includes in a jelly liquid with glycerin, sorbitol, xylitol, aloe, polyacrylate, xanthan gum; also, lactoferrin is parts of this product.

This pilot registry study evaluated in a simple, low-cost in vivo, 
natural model the effects of these 'virucidals' on the local presence in the mouth 'incubator' (saliva) of the COVID virus. As indicated, these subjects were asymptomatic or with very minor, transient symptoms (sore throat, infrequent cough and mild fatigue). A 'virucidal' mouth wash had been suggested - 3-4 times, daily - to relieve the minor symptoms. After an initial swab (day zero) the COVID-19 tests were repeated after 3 days in the same conditions. Subjects did not use food or drinks before the test to avoid an alteration of the test.

Tolerability was very good for all. No side effects were observed (for any product). Table 3 and Figure 1-2 shows the decrease in positivity in the swab samples and the percent of positive cases at 3 days. At the moment viral load is not easily measurable therefore the test is either positive or negative. The use of 'virucidals' resulted in a significant level of complete disappearance of positivity in most subjects at 3 days. All virucidals resulted effective even in these limited samples. The pharmaceutical form of the products used in this experience seems to be important to assure persisting traces of the virucidal in the mouth. PR lozenges with their gummy composition appear to produce the longest action ( $>3$ hours) due to a slower release and persistence on oral mucosa. These observations indicate a significant positive effect of virucidals on the viral contamination of the mouth with a relatively simple, costeffective model. The lower presence of a virus (even in absence of a charge measurement) or its decrease may significantly reduce contagiousness of most of these patients and the spread of viral material.

Prevention of external spread. The effects on the evolution of COVID-19 on single patients is, at the moment, unpredictable with this model but virucidals may assume a significant community value in preventing and controlling spreading.

Prevention of inner spread. It is possible to consider that from the saliva with its high viral content (while the mouth is acting as a viral growing chamber), the viral particles are aerosolized into the respiratory tract and into the lungs. The containment of viral growth in the mouth may also halt the auto-spreading of the virus from the mouth to the trachea and into the bronchial tree.

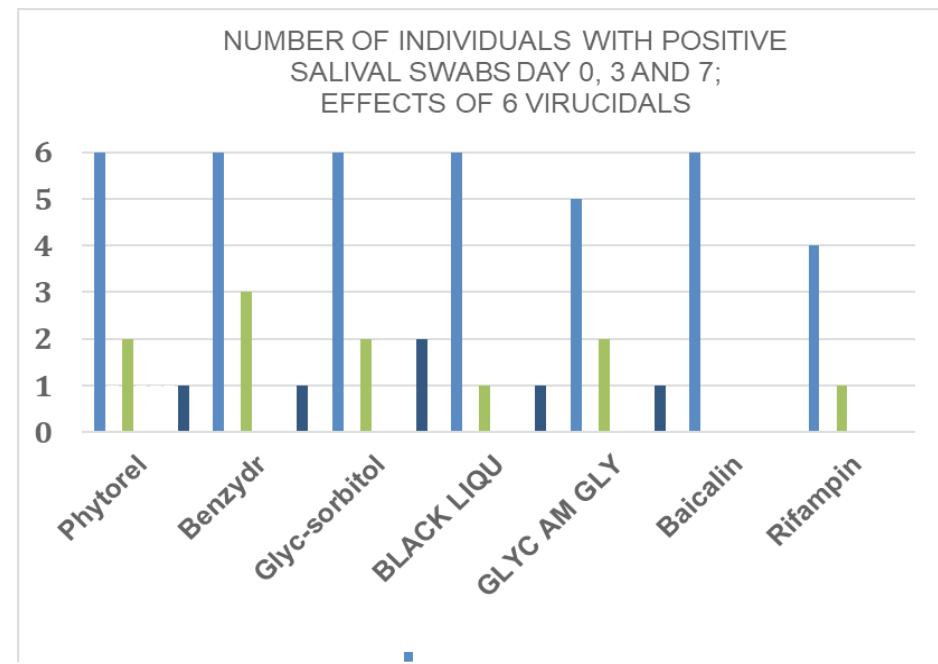

Figure 1: The Decrease in Positivity in The Swab Samples. The use of 'virucidals' resulted in a significant level of complete disappearance of positivity in most subjects.

All virucidals were effective. The gummy Phyto relief produced the longest action due to a slower release of its components. These preliminary data indicate a significant effect of virucidals on the viral contamination of the mouth/saliva with a relatively simple model. The lower presence of a virus charge or its decrease may significantly reduce contagiosity of most of these patients.

\section{Comments}

Antiviral drugs are the key drugs used for treating viral infections. Most antivirals target specific viruses; however, some broadspectrum antivirals may be effective against a wide range of viruses. Antivirals do not directly destroy their target virus but, generally, inhibit their development. At the moment there are no specific antivirals, strongly active against the Wuhan virus.

Virucides (or viricides) are not used as systemic drugs but deactivate or destroy many viruses inside or outside the body and specifically in 'border' anatomical areas (mouth, nose) when it is possible to apply them without causing damages or side effects.

Some of the most common virucidals are produced from natural plant extracts (pomegranate, eucalyptus and Australian tea trees) [13]. Eucalyptus extracts (as Calyptol, Sanofi) has been the first product (and the most common product) used with WHV (warm-humid vaporization) in our studies aimed to control the COVID virus. Calyptol produced a complete and fast temporary negativization of swabs (in 9 out of 9 subjects) and it is considered the 'model', safe virucidal to be used for viral respiratory diseases.

It is generally effective even for COVID patients in warm-humid vaporization. Virucidals have been neglected: they are cheap, generally not protected by patents and basically have an adjuvant role in a low-cost market. The real mission - almost impossible at the moment - is to kill the virus, as soon as possible in the body and outside, without side effects. Killing the virus early, in a preventive phase, could be the best option. Advanced disease, with all its clinical complications, appear difficult to manage. We have to deal, probably, with this COVID problem for a long time in prediction models [18].

The use of sequential antivirals at low-dose as a prevention may be more effective, safer and cheaper that the use of one simple antiviral. The combination of virucidal to block the viral spread and low-dose antivirals, if possible, with other treatments may be possible solutions to control viral spread $[19,20]$.

It is possible that the virus accumulates and grows in salivary glands in some patients; these situations are very difficult to eradicate. The presence of viruses in the salivary glands may induce a longer period of contagiousness and may be associated to superspreading with individuals infecting for a long period of time a large number of individuals. In case of swelling, pain at the salivary glands, in asymptomatics a swab after massaging the salivary glands may be needed. Virucidals, used more often, early and more aggressively, may help in decrease contagiousness. 
Mouth risk of viral diffusion in asymptomatic patients is very high. The role of oral mucosa in COVID-19 infection and salivary glands in the epidemic process of asymptomatic infections is documented (19). ACE2, the important receptor for COVID-19, is very common in salivary gland epithelial cells; these cells have a high expression of ACE2 and can be easily infected. The expression of ACE2 in salivary glands is higher than in lungs; this suggests that salivary glands are a premium target for COVID-19 and act as incubators.

SARS-CoV RNA is detected in saliva (the first incubator) before lung lesions. This partially explains the presence of asymptomatic infections and spreaders. For SARS-CoV, the salivary glands are, possibly, a major and neglected source of viruses migrating into saliva. The positive rate of COVID-19 in infected patients' saliva can reach $91.7 \%$, and saliva samples are used to cultivate the live virus. COVID-19 may be transmitted by subjects with asymptomatic infections that originate, very often, from infected saliva.

Most, persisting symptomatic infection (associated to superspreading) might be from salivary glands. Virucidals (Table 3 ) act where the virus is incubated and may have a very high community and management value. In conclusion, virucides including PR - may neutralize the virus in primary incubators (mouth, saliva, salivary glands) and reduce the possibility of contamination. PH appears to be a very good option with its persisting action and adhesivity in the mouth.

The virucidal study [4].

\section{VIRUCIDALS CONTROL THE PRESENCE OF} COVID IN MOUTH/SALIVA.

This was a new comparable study: subjects (swab-positive) with no symptoms or very minimal symptoms, not using other products or drugs.

In this study tolerability was very good and no side effects from virucidals were observed. Table 4 and Figure 1-2 shows the decrease in positivity in the swab samples and the percent of positive cases at 3 days. The use of 'virucidals' resulted in a significant level of complete disappearance of positivity in most subjects at 3 days. The test was considered only as positive or negative. All these virucidals resulted effective.

The pharmaceutical form was important to assure persisting traces of the virucidal in the mouth. PR in this study produced the longest action due to its slower release and persistence on the mucosal surfaces. These observations indicate a significant effect of virucidals on the viral contamination of the mouth with a relatively simple model. The lower presence of a virus charge may significantly reduce spread from these patients.

Table 4: Results of the Use of Virucidals at 3 Days

\begin{tabular}{|l|c|c|c|c|c|}
\hline PRODUCTS & PR & BENZYDR & BAICALIN & CALYPTOL & ALDIAMED \\
\hline $\begin{array}{l}\text { INCLUSION } \\
\text { Number cases }\end{array}$ & 11 & 8 & 6 & 10 & 4 \\
\hline 3 DAYS & 1 & 1 & 3 & 1 & 1 \\
\hline$\%$ POSITIVES & 9,09 & 37,5 & 16.610 & 10 & 25 \\
\hline
\end{tabular}

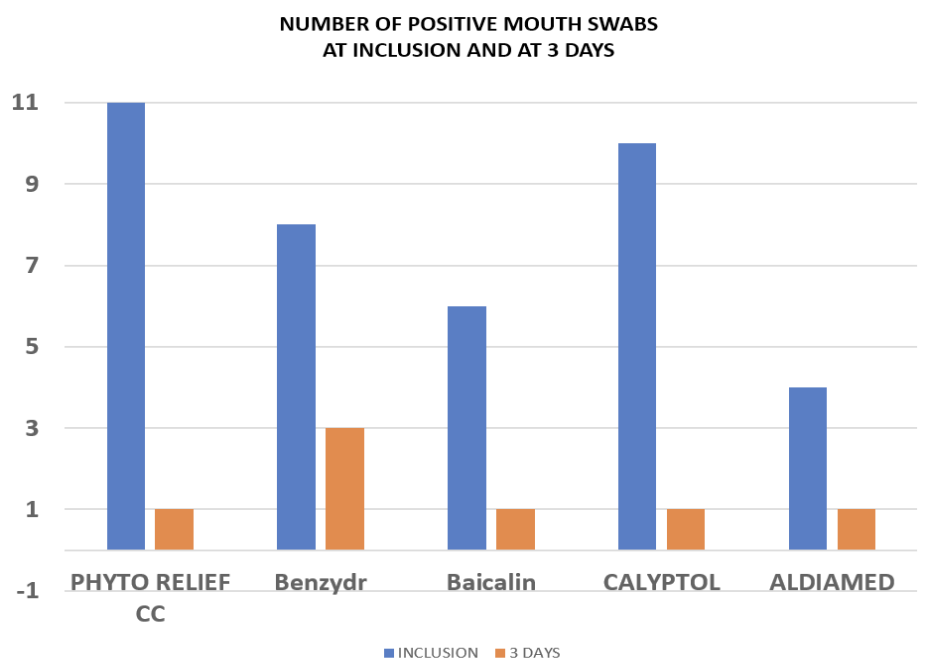

Figure 2 : \% of positive mouth tests at 3 days after using the virucidal 4 times daily.

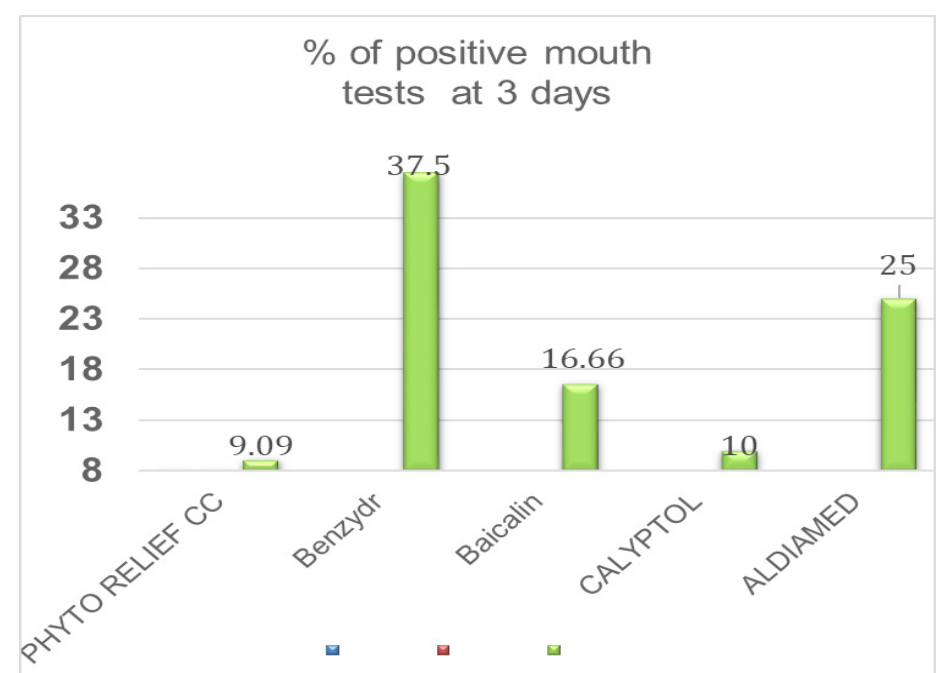

Figure 3: $\%$ of positive mouth tests at 3 days after using the virucidal 3-4 times daily. 
EFFECTS ON MOUTH-THROAT BACTERIA OF PR. THE GERMICIDAL STUDY (5). GERMICIDAL (BACTERICIDAL) POWER OF PHYTO-RELIEF (ON GROUP A B-HEMOLYTIC STREPTOCOCCUS). This concept, pilot study studied the effects of some bactericidal products in vivo to evaluate the presence of Group A $\beta$-hemolytic streptococcus (GAS) in throat swabs. With this model, if an asymptomatic subject is swab-positive, bactericidal products can be used (i.e., for 3 to 7 days) and the positivity re-evaluated to define the direct killing power of the product.

Results indicated a progressive decrease in positivity in the swab samples. Bactericidal products (PR, in 2 different formulations, Baicalin, Rifampin and Benzydamine produced the disappearance of positivity in most subjects at 3-7 days. All oral bactericidal used in this registry resulted effective killing bacteria in $>85 \%$ of cases.

The pharmaceutical form (gummy, slow release lozenges) of Phyto-Relief seems to be important to assure persisting traces of the bactericidal/virucidal in the mouth mucosa. Phyto-Relief lozenges possibly, produced the longest action ( $>3$ hours) due to the slower release of the substances (mainly pomegranate and ginger) in the product.

These observations indicate a significant effect of bactericidals on Group A $\beta$-hemolytic streptococcus as previously seen on the viral contamination of the mouth with a relatively simple, cost-effective human model. The lower presence of a bacterial and virus charge and its decrease may reduce contagiousness of most of these patients and possibly, the spread of bacterial/viral material from the mouth of affected subjects, particularly asymptomatic subjects. The effects on the evolution of infections on single patients is, at the moment, not fully predictable with this model but oral bactericidal and virucidals may assume a significant community value in preventing and controlling spreading.

Table 5: groups composition

\begin{tabular}{|c|c|c|c|}
\hline Group 1 & $\mathbf{1 8}$ & AGE & $\mathbf{3 6 . 2 ; 2}$ \\
\hline 2 & 18 & \multirow{5}{*}{} & $35.3 ; 2.2$ \\
\hline 3 & 18 & & $35.5 ; 2.1$ \\
\hline 4 & 18 & & $36.1 ; 1.6$ \\
\hline 5 & 16 & & $36.5 ; 2.6$ \\
\hline
\end{tabular}

Table 6: data concerning the positivity of swabs in the 5 groups at different times. Arbitrarily, it is possible to define as germicidal products that reduce of $>\mathbf{8 0} \%$ the positivity of swabs in a week of 'standard' management.

PR2

\begin{tabular}{|l|c|c|c|c|c|}
\hline TIME & PR & BENZ & PR2 & BAICA & RIFAMP \\
\hline Inclusion & 18 & 18 & 18 & 18 & 16 \\
\hline 3 days & 1 & 3 & 2 & 2 & 2 \\
\hline 7 days & $1(5.5 \%)^{*}$ & $2(11.1 \%)^{*}$ & $2(11.1 \%)^{*}$ & $2(11.1 \%)^{*}$ & $1(6.25 \%)^{*}$ \\
\hline${ }^{*}=\mathrm{P}<0.05 ;$ & ANOVA \\
\hline
\end{tabular}

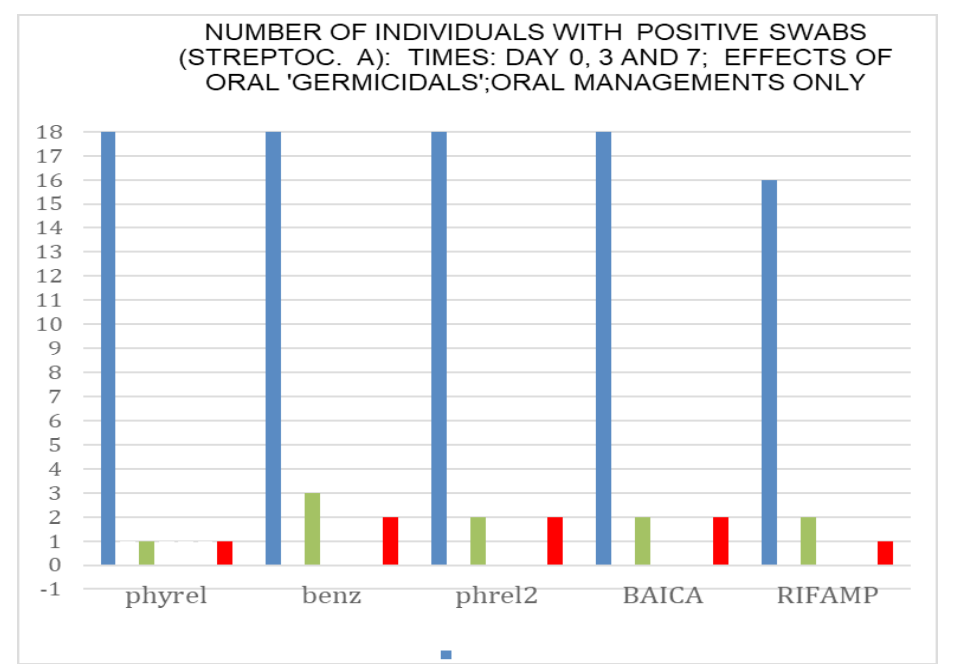

Figure 4: variations in positivity with the 5 oral 'germicidals'.

A bactericidal product is a drug or substance which kills bacteria. A virucidal has the capacity to destroy or inactivate viruses.
A substance, drug or agent that kills germs, especially pathogenic microorganisms can be defined as a germicidal; a disinfectant is a different product that cannot be used in the mouth or ingested [14-15]. Antiviral drugs and antibiotics are the key drugs used for treating bacterial and viral infections. Most antibiotics and antivirals target specific bacteria or viruses; however, some broadspectrum antibiotics and antivirals may be effective against a wide range of bacteria/viruses both in systemic administration and in local applications.

Antivirals do not directly destroy their target virus but, generally, inhibit their development. At the moment - studies are in progress - there are no specific antivirals, strongly active i.e., against the Wuhan viruses. Virucidals are not used as systemic drugs but deactivate or destroy many viruses inside or outside the body and specifically in 'border' anatomical areas (mouth, nose) when it is possible to apply them without causing damages or side effects.

Some of the most common virucidals (these products may also affect most bacteria) are produced from natural plant extracts (pomegranate, eucalyptus and Australian tea tree oil, licorice, Baicalin). Most of these products can be also used by inhalation. 
Eucalyptus extracts (as Calyptol, Sanofi) has been the first product (and the most common product) used with WHV (warm humid vaporization) in our studies aimed to control the COVID virus. Phyto-relief has shown remarkable activity against the aggressive COVID-19 virus.

This registry had the aim of evaluating a possible bactericidalgermicidal activity on a very common micro-organism (GAS) present, in asymptomatic form, in many subjects. The fast, but possibly, temporary negativization of swabs in this registry may be considered a model to study the germicidal and virucidal activity of locally-acting oral compounds (that can also be ingested). Germicidals and virucidals have been neglected: they are cheap, generally not protected by patents and basically, have an adjuvant role in a low-cost market.

The real target is to kill bacteria and viruses (including the COVID virus) without side effects and in early phases of contamination. Killing bacteria and any virus early, in a preventive phase, could be the best option to avoid spreading.

Advanced diseases, with all its clinical complications (both for bacterial infections and viral problems) appear much more difficult to manage [16].

The combination of virucidals to block the viral spread (particularly for the COVID) and low-dose antivirals with other treatments may be possible solutions to control viral spread. In URT viral infection aerosolization has been also neglected as an important therapeutic method. Recent studies indicate that it is possible to affect the presence of several viruses, particularly COVID, with warm $\left(60^{\circ} \mathrm{C}\right)$ and humid vaporization. COVID 19 shows a significant weakness to increased temperature exposure and may be destroyed by a humid and warm vapor. The jet produced by vaporizers (Prontex) sends a jet at $60 \mathrm{C}^{\circ}$. Within the higher temperature jet many substances solubilize very easily. The specific thermolability of COVID 19 has been shown in several studies but it has not been fully exploited from a clinical point of view. The warm vapor arrives directly in the anatomical areas mostly affected by viruses attacking the URT.

The vaporization of several products into the URT - i.e., caliptol, baicalin, hydroxychloroquine (normal suggested dose 200-400 $\mathrm{mg}$ salt; 155 to $310 \mathrm{mg}$ base/day orally divided in 1 or 2 doses or colchicine capsules (normal dose: $0.6 \mathrm{mg}$ once-twice daily) - allows to reduce the oral doses by 20 to 50 times reducing or abolishing side effects.. The maximum dose is $1.2 \mathrm{mg}$ per day. Vaporization may kill viruses, including COVID, directly in the URT limiting external and internal spread. Warm vaporization allows the administration of several compounds directly into the respiratory system (corticosteroids). A pharmacological effect can be obtained with a dose some 20-50 times lower than the normal systemic dose.

A liquified preparation of PR was also tested with warm vaporization in 8 subjects. The virucidal effect was confirmed in a limited number of COVID cases (data on file). The vaporization was well tolerated. Aerosolization was significantly effective as a viricidal with improvement of (mild) signs and symptoms. This aspect needs a better evaluation in a large number of subjects.
The evaluation of the effects of oral PR on COVID - both as a lozenges and with vaporization - is now in progress. A registry on elder subjects in resting homes is in progress at the moment and preliminary results will available in a short period of time.

\section{Global Evaluation}

PR appears to be effective as a virucidal and a selective germicidal (bactericidal) product - but more clinical or pre-clinical preventive studies are needed. PR helps preventing a number of episodes of cold and flu and limits symptoms and the duration of the URT problem. The OTC product can be used without prescription and it appears to be generally effective on signs/symptoms of viral infections.

PR has a good preventive value. No side effects or tolerability problem were observed. The important virucidal and germicidal activities need larger, more prolonged evaluations in different group of subjects and patients and in variable clinical contexts associated to viral infections.

With predictive analytics and careful planning, it is possible to show the virucidal-bactericidal effects (and their clinical preventive efficacy) of PR in weeks, in controlled supplement studies with groups of 40 subjects. The planning (or the final management) of these supplement studies are now in progress $[32,33]$.

\section{References}

1. Luzzi R, Belcaro G, Pellegrini L, Cornelli U, Feragalli B, et al. (2015) Phyto-relief CC: prevention of cold episodes. Control of signs/symptoms and complications. Minerva Gastroenterol Dietol.

2. Belcaro G, Pellegrini L, Cornelli U, Feragalli B, Dugall M, et al. (2015) Phyto-relief CC: prevention of cold episodes. Control of signs/symptoms and complications in immunocopromised subjects. Minerva Gastroenterol Dietol.

3. Belcaro G, Cornelli C, Cesarone MR, Feragalli B, Cotellese $\mathrm{R}$, et al. (2020) Decrease in COVID-19 Contagiousness. Virucidals Control the Presence of COVID in Saliva and Salivary Glands Med Clin Res 5: 1-4.

4. Belcaro G, Bombardelli E, Cornelli U, Cesarone MR, Cotellese R, et al. (2020) Virucidals Control the Presence of COVID in Mouth/Saliva. Med Clin Res 5: 6-10.

5. Belcaro G, Cornelli U, Cesarone MR, Cotellese R, Dugall, et al. (2020) Germicidal (Bactericidal) Power of Phyto-Relief (On Group A B-Hemolytic Streptococcus); a Concept, Pilot Registry. Med Clin Res 5: 118-120.

6. 2019 Novel Coronavirus (2019-nCoV) Situation Summary" (2020) Centers for Disease Control and Prevention.

7. Real-Time RT-PCR Panel for Detection 2019-nCoV (2020) Centers for Disease Control and Prevention. Curetis Group Company Ares Genetics and BGI Group Collaborate to Offer Next-Generation Sequencing and PCR-based Coronavirus (2019-nCoV) Testing in Europe". GlobeNewswire News Room.

8. J Xu, Y Li, F Gan (2020) Salivary Glands: Potential Reservoirs for COVID-19 Asymptomatic Infection. https:// doi.org/10.1177/0022034520918518.

9. Xu J, Li Y, Gan F, Du Y, Yao Y (2020) Salivary Glands: Potential Reservoirs for COVID-19 Asymptomatic Infection. 
J Dent Res.

10. "The definition of virucide" (2017) Reference.com.

11. US EPA, OCSPP (2020) "List N: Disinfectants for Use Against SARS-CoV-2". US EPA.

12. Boyce JM, Pittet D (2020) "Guideline for Hand Hygiene in Health-Care Settings. Recommendations of the Healthcare Infection Control Practices Advisory Committee and the HICPAC/SHEA/APIC/IDSA Hand Hygiene Task Force. Society for Healthcare Epidemiology of America/Association for Professionals in Infection Control/Infectious Diseases Society of America" (PDF). MMWR. Recommendations and Reports 51: 1-45.

13. Sauerbrei A, Wutzler P (2010) "Virucidal efficacy of povidone-iodine-containing disinfectants". Letters in Applied Microbiology: no-no.

14. Horhammer L (2020) Hager's Handbuch der Pharmazeutischen Praxis, Vols. 2-6, Springer-Verlag, Berlin, 1969-1979

15. Sodeik B, Griffiths G, Ericsson M, Moss B, Doms RW (1994) "Assembly of vaccinia virus: effects of rifampin on the intracellular distribution of viral protein”. J Virol 68: 11031114.

16. Schnitzler P, Schön K, Reichling J (2001) “Antiviral activity of Australian tea tree oil and eucalyptus oil against herpes simplex virus in cell culture". Die Pharmazie 56: 343-347.

17. Belcaro G, Cornelli U, Cesarone MR, Feragalli B, Bombardelli E, et al. (2020) Spread of Respiratory Viruses: Temperature and Physical Environment. Temperature Control May Exploit Virus Hypo-Thermolabity; A Possibile, Immediate Solution for COVID-19. Med Clin Res 5: 30-33.

18. Xu J, Li Y, Gan1 M, Du Y, Yao Y (2020) Salivary Glands: Potential Reservoirs for COVID-19 Asymptomatic Infection. J Dental Research.

19. Belcaro G, Cesarone MR, Cornelli U (2020) La Prossima Epidemia. Min Medica, Turin.

20. Vakkila J, Koskinen J, Brandt A, Muotiala A, Liukko V (2015) Detection of Group A Streptocccus from Pharyngeal Swab Samples by Bacterial Culture Is Challenged by a Novel mariPOC Point-of-Care Test. J Clin Microbiol 53: 2079-2083.

21. Thompson TZ, McMullen AR (2020) Group A Streptococcus Testing in Pediatrics: the Move to Point-of-Care Molecular
Testing. J Cl Microbiol 58: e01494-e01419.

22. O Luiz FB, Alves KB, Barros RR (2019) J Prevalence and long-term persistence of beta-haemolytic streptococci throat carriage among children and young adults. Med Microb 68: 1526-1533.

23. Wang H, Hui KM, Xu S, Chen Y, Wong JT, et al. (2002) "Two flavones from Scutellaria baicalensis Georgi and their binding affinities to the benzodiazepine site of the GABA receptor complex". Pharmazie 57: 857-858

24. Boyce JM, Pittet D (2002) Healthcare Infection Control Practices Advisory Committee, HICPAC/SHEA-APIC/IDSA Hand Hygiene Task Force. "Guideline for Hand Hygiene in Health-Care Settings 51: 1-45.

25. Tarragó T, Kichik N, Claasen B, Prades R, Teixidó M, et al. (2008) "Baicalin, a prodrug able to reach the CNS, is a prolyl oligopeptidase inhibitor". Bioorganic \& Medicinal Chemistry 16: 7516-7524.

26. Sodeik B, Griffiths G, Ericsson M, Moss B, Doms RW (1994) Assembly of vaccinia virus: effects of rifampin on the intracellular distribution of viral protein p65. J Virol 68: 11031114.

27. Sauerbrei A, Wutzler P (2010) Virucidal efficacy of povidoneiodine- containing disinfectants. Letters in Applied Microbiology 51: 158-163.

28. Horhammer L (1928) Hager's Handbuch der Pharmazeutischen Praxis. The Journal of the Amer Pharmac Association 17: 318-319.

29. Thomas L, Sekhar Miraj S, Surulivelrajan M, Varma M, Sanju CSV, et al. (2020) Influence of Single Nucleotide Polymorphisms on Rifampin Pharmacokinetics in Tuberculosis Patients. Antibiotics (Basel) 9: E307.

30. McMurray RL, Ball MEE, Tunney MM, Corcionivoschi N, Situ C (2020) Antibacterial Activity of Four Plant Extracts Extracted from Traditional Chinese Medicinal Plants against Listeria monocytogenes, Escherichia coli, and Salmonella enterica subsp. enterica serovar Enteritidis. Microorganisms 8: E962.

31. Siegel E (2013) Predictive analytics. Wiley, Hoboken, NJ.

32. Cox Dr (1961) Planning of Experiments. Wiley, Jan 15th, 1961 Oxford.
Copyright: (C2021 Cesarone MR. This is an open-access article distributed under the terms of the Creative Commons Attribution License, which permits unrestricted use, distribution, and reproduction in any medium, provided the original author and source are credited. 